\title{
An Overview of Synthesis Based Biomedical Applications of Hydroxyapatite Nanomaterials
}

\author{
Netra Lal Bhandari ${ }^{* 1}$, Sunita Bista ${ }^{1}$, Tika Ram Gautam ${ }^{1}$, Kabita Bist ${ }^{1}$, Ganesh Bhandari ${ }^{1}$, \\ Sumita Subedi², Kedar Nath Dhakal ${ }^{3}$ \\ IDepartment of Chemistry, Tri-Chandra Multiple Campus, Tribhuvan University, Kathmandu, Nepal \\ ${ }^{2}$ Department of Chemistry and Chemical Engineering, Inha University, Incheon, South Korea \\ ${ }^{3}$ Central Department of Chemistry, Tribhuvan University, Kirtipur, Kathmandu, Nepal \\ CorrespondingE-mail: netra.tu.edu@gmail.com
}

(Received: August 20, 2020; Revised: October 28, 2020; \& Accepted: December 7, 2020)

\begin{abstract}
Hydroxyapatite (HAp) is the mineral phase of animal bones embedded in the collagen-containing organic matrix of the bones. It is a naturally optimized material that provides physical support to the bones. Hydroxyapatitebased biomaterials, hence, find wide biomedical applications especially in orthopedics, dentistry, and tissue engineering due to their biocompatibility, bioactivity, osteoconductivity, and similar chemical composition of HAp to that of minerals present in animal bones. Different physicochemical synthetic methods and available natural biogenic sources have been reported for the preparation of nano-HAp. However, particle size, aspect ratio, morphology, crystallinity, and the distribution of HAp in biomaterials have significant effects on their biomedical applications. This paper has summarized some methods of extraction of nano-HAp from different biogenic sources including bio-wastes. Furthermore, it focuses on some facile wet chemical synthetic routes of preparing nano-HAp with controlled particle size and morphology, higher crystallinity, and native bone architectures. This review article aims to correlate some simplistic and cost-effective biosynthetic approaches of nano-HAp, its properties, characterization techniques, and its size and morphology-dependent biomedical applications.
\end{abstract}

Keywords: Hydroxyapatite, wet chemical methods, sustainable biogenic sources, biomedical applications

\section{Introduction}

Hydroxyapatite (HAp) $\left[\mathrm{Ca}_{10}\left(\mathrm{PO}_{4}\right)_{6}(\mathrm{OH})_{2}\right]$, one of the specially developed bio-ceramics, composed of major components of the animal bones and teeth is widely used for biomedical applications and dental implants [1-5]. HAp contains calcium, hydroxyl groups, and phosphate groups as its major components in crystalline form and has hexagonal crystal structure as shown in Figure 1 [6]. The calcium to phosphorous molar ratio 1.67 is taken as the best one for its biomedical applications specially in bone regeneration and substitution. HAp is present in animal bones being connected with organic collagen fiber (matrix). Its biocompatibility, non-toxicity, osteoconductivity, and similar chemical composition and structure to the natural bones, host response in a biological environment etc, attracts the attention of scientists to prepare it as an essential biomaterial in tissue engineering, bone fillers, soft tissue component, in drug delivery systems, etc. [4,7-12]. On the other hand, its poor mechanical and rheological properties have attracted other biomaterials for their combination to generate strong and high-value hybrid biomaterials [3,13-17]. Though it is limited in direct load bearing applications, it is widely used for biomedical applications as a bone graft substitute and implant coating agent [18]. HAp based biocompatible hybrid materials have received considerable attention in this regard because of hemostatic properties, bone healing functions and their ability to mimic natural bones [16,17]. However, the size, morphology, and crystallinity of HAp particles greatly alter the functional performance of these biomaterials in biomedical applications mostly in bone regeneration, reconstruction and replacement [19].

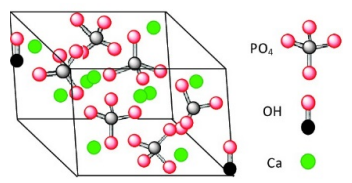

Figure 1: Crystalline structure of hydroxyapatite and its basic components [6] 
Incorporation of dual bioactive ions into nanoHAp particles produces biomaterials with improved bioactivities and osteo-conduction applicable for line cell imaging [20]. Nano-sized HAp better improves cytophilicity and possesses greater bioactivities, biosorption and proliferation to bone marrow optimizing biological functionality if compared to conventional micro/macro-sized HAp $[19,21,22]$. Similarly, crystalline HAp provides a comparatively suitable substrate to mesenchymal cells of bone marrow in terms of their adhesion, proliferation, and differentiation to osteoblasts than amorphous HAp even with their comparable size [23]. Rod and needleshaped HAp particles disperse better in a matrix than spherical, cuboidal, and mixed shaped HAp [24]. Hence, crystalline structure with precisely controlled nano-size, phase, morphology, composition, $\mathrm{Ca} / \mathrm{P}$ ratio, etc. are the fundamental criteria for HAp to find biomedical applications [23]. On the other hand, the limitation of its poor mechanical and compressive strength can be overcome by its combination with natural and biocompatible polymers to prepare elastic and tough biomaterials for biomedical applications. $[9,22]$. Synthetic conditions and parameters (mostly in wet chemical methods) such as concentration, temperature, $\mathrm{pH}$ value, addition rate of reactants, solvent system, drying conditions, etc. adopted for the preparation of HAp greatly affect the particle size, morphology, crystallinity, and calcium to phosphorous ratio of the materials $[25,26]$. Similarly, the conditions employed for the extraction of HAp from biogenic sources alters the size, phase and geometry of HAp particles [27,28], HAp, as an essential nanomaterial for the preaparation of most of the high-value biomaterials of biomedical importance can be prepared via facile routes from various naturally available biogenic sources (including bio-wastes) and some wet chemical synthetic methods in ordinary laboratories [29]. Such biogenic sources include egg shells, animal bones, sea shells, fish scales, etc, while wet chemical methods include precipitation, sol-gel, hydrothermal, hydrolysis methods etc. Moreover, these naturally available biogenic sources can be the potential and sustainable HAp-sources leading to the biomedical applications with ecological management (explained later) [29-32].

This review article summarizes the methods of preparating nano-HAp adopting facile wet chemical techniques and its extraction from naturally available biogenic sources (bio-wastes) in a cost effective way, characterization of their composition, structure and morphology, and size and crystallinity dependent biomedical applications of related bio-nanomaterials.

\section{Facile preparation of HAp}

Different mechanochemical, wet chemical, and thermal techniques of HAp synthesis are reported in literatures. Some facile wet chemical methods and biogenic sources of preparing nano-HAp in an ordinary chemistry laboratory are discussed here.

\section{Wet chemical routes}

It comprises different synthetic routes such as precipitation, sol-gel, hydrolysis, hydrothermal, sonochemical, emulsion method etc, [18,33-39]. All of these methods can be employed to produce crystalline HAp, however, some of them require thermal treatment of the materials at elevated temperature for higher crystallinity. Meanwhile, phase and morphology transformation may occur at higher tremperature [26,40]. Different wet chemical parameters such as the concentration of starting solutions, the addition rate of reactants, temperature, $\mathrm{pH}$ value, etc. should be controlled to produce monophase crystalline HAp [41]. Precipitation and sol-gel methods are summarized here as facile wet chemical methods of preparing crystalline HAp.

\section{a) Precipitation method}

It is the mostly used wet chemical technique for the synthesis of HAp by the precipitation reaction using calcium oxide $(\mathrm{CaO})$, ortho-phosphoric acid $\left(\mathrm{H}_{3} \mathrm{PO}_{4}\right)$, calcium hydrogen phosphate $\left[\mathrm{Ca}\left(\mathrm{H}_{2} \mathrm{PO}_{4}\right)_{2}\right]$, ammonium hydrogen phosphate $\left[\left(\mathrm{NH}_{4}\right)_{2} \mathrm{HPO}_{4}\right]$ as calcium and phosphorous precursors $[41,42]$. The chemical reactions occurring in this method are presented as follows [29,37].

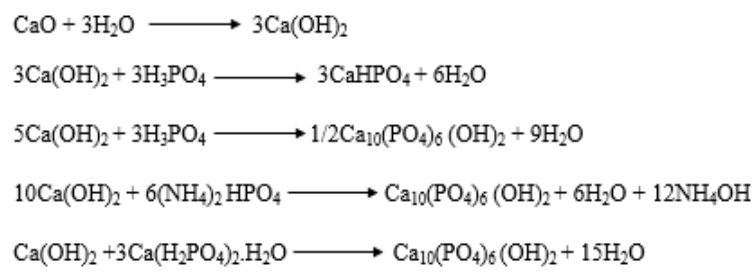

Hence, nano-HAp can easily be prepared via. precipitation method, however various factors greatly affect the resulting HAp particles. $\mathrm{pH}$ value and temperature affect the HAp phase (Ca-deficient, oxyHAp and carbonated HAp) while drying methods, solvent systems, and dispersant species affect size, morphology, crystallinity, homogeneity, and dispersibility of the particles $[25,26,40]$. Suitable solvents and concentration of solutions and controlled $\mathrm{pH}$ value should be employed to achieve a suitable $\mathrm{Ca} / \mathrm{P}$ ratio (1.67) because most of the thermal and biomedical properties of the materials depend on this ratio. HAp with this standard $\mathrm{Ca} / \mathrm{P}$ ratio is thermally stable up to $1400^{\circ} \mathrm{C}$ but Ca-deficient HAp converts 
into ß-tri-caclcium phosphate (TCP) at $900^{\circ} \mathrm{C}$ [26]. Drying and sintering temperature can be increased for the hardness of materials, however, needle-like morphology (the best suitable for biomedical applications) can be transformed into spherical morphology [40]. Therefore, the 'Heat and Trial' method as well as 'Single Factor Test Method' can be adapted to determine the particular conditions of these parameters and minimize above mentioned effects. Another most significant way is to use capping agents in the reaction mixtures which avoid individual particles from nucleation (agglomeration) and modification of size, shape, and morphology [40-43]. Zhang et al. has reported the sodium salt of carboxymethyl cellulose (CMC) approach to control the HAp particle size in co-precipitation method. HAp particles with suitable size and orientation to human bones can be prepared adopting this approach. $\mathrm{CMC}$ molecules attract $\mathrm{Ca}^{++}$ions from $\mathrm{HAp}$ by chelation effect forming $\mathrm{Ca}-\mathrm{CMC}$ complex which controls the agglomeration of HAp [44].

\section{b) Sol-gel method}

The sol-gel method is taken as an efficient and attractive method from economic point of view for the preparation of HAp with higher bioresorbsability and resembling to bone apatite [45]. In this method, solutions of calcium and phosphorous precursors (source of calcium and phosphorous) are used for the preparation of HAp. Aging of these calcium and phosphorous precursor solutions at low temperature to obtain a sol followed by at higher temperature producing a gel is carried out due to which it is named as sol-gel method. Calcination of gel thus obtained at elevated temperature produces HAp [45,46] The mostly used Ca-precursors are calcium nitrate $\left[\mathrm{Ca}\left(\mathrm{NO}_{3}\right)_{2}\right]$ and calcium diethoxide $\left[\mathrm{Ca}(\mathrm{OEt})_{2}\right.$ whereas P-precursors are ammonium hydrogen phosphate $\left[\left(\mathrm{NH}_{4}\right)_{2} \mathrm{HPO}_{4}\right]$, triethyl phosphate $\left[\left(\mathrm{C}_{2} \mathrm{H}_{5}\right)_{3} \mathrm{PO}_{4}\right]$ and triethyl phosphite $\left[\left(\mathrm{C}_{2} \mathrm{H}_{5}\right)_{3} \mathrm{PO}_{3}\right]$. Corresponding solutions of these materials are mixed together in dropwise manner with vigorous stirring under controlled $\mathrm{pH}$ and temperature. Continuous stirring of reaction mixture produces an aged gel which is washed until neutral $\mathrm{pH}$ and dried. The chemical reaction involved in this method are as follows $[29,30,45,47]$.

$$
\begin{gathered}
10 \mathrm{Ca}\left(\mathrm{NO}_{3}\right)_{2}+6\left(\mathrm{NH}_{4}\right)_{2} \mathrm{HPO}_{4}+8 \mathrm{NH}_{4} \mathrm{OH} \underset{\mathrm{pH}}{75^{\circ} \mathrm{C}} \longrightarrow \mathrm{Ca}_{-11} \\
\left.\mathrm{Ca}\left(\mathrm{NO}_{3}\right)_{2}+\left(\mathrm{C}_{2} \mathrm{H}_{5}\right)_{3} \mathrm{PO}_{4} \longrightarrow \mathrm{PO}_{4}\right)_{6}\left(\mathrm{OH}_{2}+20 \mathrm{NH}_{4} \mathrm{NO}_{3}+6 \mathrm{H}_{2} \mathrm{O}\right. \\
\longrightarrow \mathrm{Ca}_{10}\left(\mathrm{PO}_{4}\right)_{6}(\mathrm{OH})_{2}+\text { Biproducts }
\end{gathered}
$$

The size and crystallinity of HAp produced also depend upon the medium (ethanol and water) along with other parameters like temperature, $\mathrm{pH}$, etc, $[41,48]$. Figure 2 shows the synthetic scheme of HAp from the sol-gel method [45].

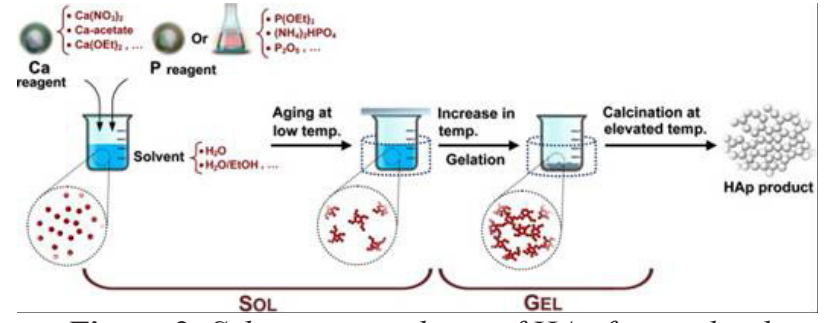

Figure 2: Schematic synthesis of HAp from sol-gel method [45]

\section{II) Biogenic routes}

Crystalline nano-HAp for biomedical and clinical applications can be extracted from different biogenic sources and bio-wastes adopting different mechanochemical methods [49]. These sources include animal sources (bones, egg shells, etc.), plant sources (fruit peels, leaves, stems, roots, etc), and aquatic sources (corals, sea shells, fish scales/bones, etc.) [50]. Animal and aquatic sources contain HAp in maximum whose calcination gives nano-HAp. Similarly, eggshells are rich in $\mathrm{CaCO}_{3}$ content from which $\mathrm{CaO}$ can be derived which can be further converted into HAp as follows;

$$
\begin{aligned}
& \mathrm{CaCO}_{3} \stackrel{1000^{\circ} \mathrm{C}}{\longrightarrow} \mathrm{CaO}+\mathrm{CO}_{2} \\
& \mathrm{CaO}+6 \mathrm{H}_{3} \mathrm{PO}_{4} \longrightarrow \mathrm{Ca}_{10}\left(\mathrm{PO}_{4}\right)_{6}(\mathrm{OH})_{2}+8 \mathrm{H}_{2} \mathrm{O}
\end{aligned}
$$

Different bio-wastes are used for the extraction of HAp via calcination method. Table 1 presents various animal bones, and the related parameters for the extraction of HAp through calcination and sintering.

Table 1: Various animal bones as sources of HAp via calcination and sintering

\begin{tabular}{lccc}
\hline Bio-wastes & $\begin{array}{c}\text { Temperature } \\
\left({ }^{\circ} \mathbf{C}\right)\end{array}$ & $\begin{array}{c}\text { Time } \\
(\text { hour })\end{array}$ & References \\
\hline Fish bones & 1300 & - & {$[51]$} \\
Pig bones and & 650,1050 & 2 & {$[52]$} \\
pig teeth & & & \\
Human teeth & 650,1050 & 2 & {$[52]$} \\
Bovine bones & 750 & 6 & {$[53]$} \\
Buffalo bones & 1000 & 6 & {$[54]$} \\
Camelus bones & 1000 & - & {$[55]$} \\
Pigeon bones & 1050 & 2.5 & {$[56]$} \\
\hline
\end{tabular}

Extraction of HAp from various biogenic raw materials require different calcination temperatures time and slightly different procedures. Crystalline HAp can be obtained from these biogenic routes [5156]. Scheme 1 presents the extraction of HAp powder from buffalo bones.

\section{Comparison of synthetic and bio-derived HAp}

Physicochemical and morphological properties of HAp depend on its origin and the employed methods and conditions of preparation [27]. Natural HAp 


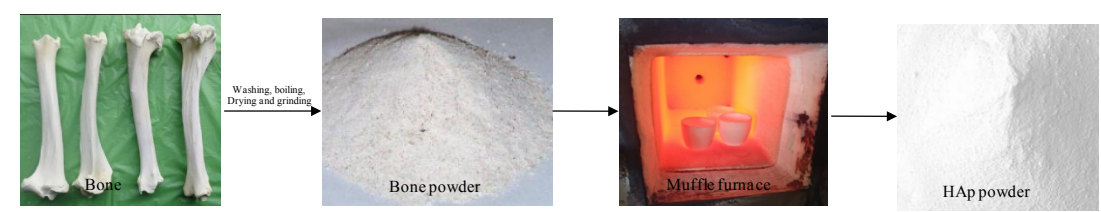

Scheme 1: Experimental flow chart showing the extraction of HAp from buffalo bone

extracted from animal bones via calcination process possesses higher crystallinity whereas synthetic hydroxyapatite exhibited low crystallinity [27,28]. Similarly, HAp derived from biogenic sources much more resembles the biological apatite in morphological, structural, and compositional aspects rather than that synthesized by wet chemical methods. Additional minerals essential for human physiology such as $\mathrm{Mg}^{++}, \mathrm{K}^{+}, \mathrm{Si}^{++}, \mathrm{Na}^{+}, \mathrm{Zn}^{++}, \mathrm{Ba}^{++}$, $\mathrm{F}^{-}$etc. will be present in trace amount in bio-derived HAp that are not possible in chemically synthesized HAp. Furthermore, biogenic sources of HAp are calcium and phosphorous precursors themselves due to which HAp derived from them will be rich in the minerals of natural bones [22,24,30,50]. Therefore, it further enhances the bone restoration and bone healing process forming tight and stable bond to the bones in comparison to synthetic HAp. Biogenic sources can be sustainable sources of HAp for biomedical applications not only with better accessibility, extra osteoblast proliferation, and biocompatibility but also from the economical, ecological and environmental points of view [30,50].

\section{Characterization techniques}

X-Ray, spectroscopy, and microscopy-based techniques are generally used to investigate phase and crystallinity; chemical composition and functional groups; and morphology of HAp respectively. Spectroscopic techniques such as Fourier transform infrared (FTIR) and Raman spectroscopy are used to elucidate functional groups present in the materials and their chemical composition respectively. Similarly, X-ray photoelectron spectroscopy (XPS) provides elemental composition at parts per thousand range and information about empirical formula, and chemical and electronic state of the elements within the materials. Microscopic techniques such as scanning electron microscopy (SEM), transmission electron microscopy (TEM), and atomic force microscopy (AFM) provide information about the shape, morphology, and dispersion of HAp. X-ray diffraction (XRD) patterns show characteristic diffraction peaks of HAp at various angles to confirm the crystallinity and phase existence of the materials $[9,30,54,57-60]$.

\section{X-ray diffraction (XRD) patterns}

X-ray diffraction (XRD) patterns of chemically synthesized hydroxyapatite (C-HAp) and fish bone processed hydroxyapatite (FB-HAp) powders compared with JCPDS data are presented in Figure 3. Intense peaks with lower width of FB-HAp signify its higher crystallinity in comparison to that of C-HAp. On the other hand, few peaks of C-HAp below $25^{\circ}$ of $2 \theta$ values are not intense and distinguishable. Absence of any additional peaks and peak shifting in C-HAp corresponds to the absence of any impurities and other HAp phases. Furthermore, the most intense peak at (211) plane and $31.6^{\circ}$ of $2 \theta$ is preferentially expected during the preparation of these materials which is the characteristic peak of HAp. The width of this peak is taken into account to calculate the particle size of HAp synthesized using the Scherrer equation and employing full width at half-maximum

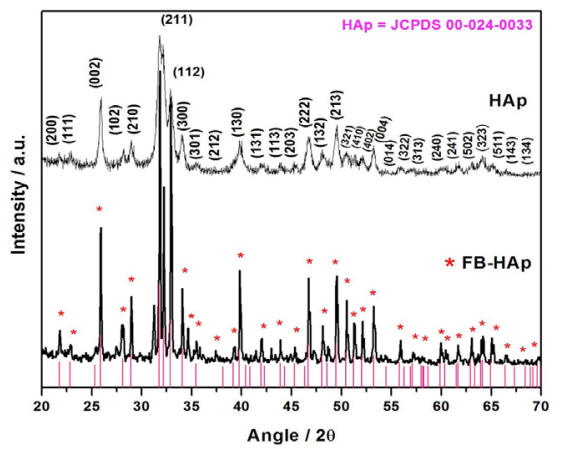

Figure 3: XRD patterns of chemically synthesized hydroxyapatite (C-HAp) and fish bone processed hydroxyapatite (FB-HAp) [30]

(FWHM) values. Peaks at miller indices (002), (210), (112), (130), (222), (213), (004) corresponding to $25.8^{\circ}, 28.8^{\circ}, 32.1^{\circ}, 39.7^{\circ}, 46.6^{\circ}, 49.4^{\circ}$, and $53.2^{\circ}$ of $2 \theta$ values respectively are the characteristic peaks of HAp mentioned by its JCPDS number $[29,30,58]$. From Figure 3 taking the most intense peak at $31.6^{\circ}$ of $2 \theta$ value, the size of HAp from the chemical process and biogenic routes (fish-bone) is found to be $88.3 \mathrm{~nm}$ and $72 \mathrm{~nm}$, respectively [30].

\section{Structural characterization}

Comparative FTIR spectra of natural (derived from femoral bones of pig) and chemically synthesized HAp are presented in Figure 4. Phosphate $\left(\mathrm{PO}_{4}{ }^{3-}\right)$ and hydroxides $\left(\mathrm{OH}^{-}\right)$are the characteristic functional groups present in $\mathrm{HAp}$. $\mathrm{OH}^{-}$groups appeared at the 


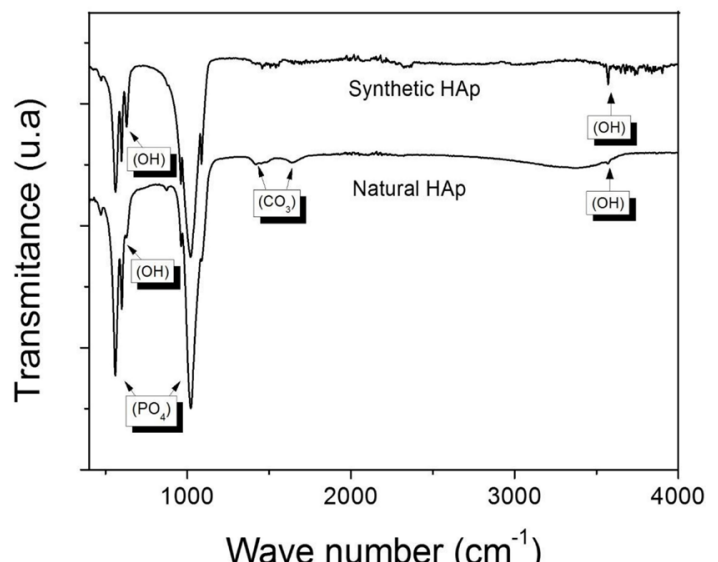

Figure 4: FTIR spectra of natural and synthetic HAp powders [58]

wave numbers $629 \mathrm{~cm}^{-1}$ and $3570 \mathrm{~cm}^{-1}$ are attributed to their bending and stretching respectively. $\mathrm{PO}_{4}^{3-}$ groups appeared at 561 and $598 \mathrm{~cm}^{-1}$ correspond to its asymmetric bending while that at 1021 and 1087 $\mathrm{cm}^{-1}$ correspond to their asymmetric stretching. The presence of $\mathrm{PO}_{4}^{3-}$ at $961 \mathrm{~cm}^{-1}$ is attributed to symmetric stretching. Carbonate $\left(\mathrm{CO}_{3}\right)^{--}$can also be present in HAp depending on the synthetic routes $[9,58]$ which is generally found intense in bio-derived HAp whereas weaker in synthetic HAp $[58,60]$.

\section{Chemical composition}

Investigation of the elemental composition of materials is carried out by XPS spectra analyses. XPS spectra are measured by the irradiation of materials with a beam of excited photons to measure kinetic energy and the number of electrons that escape $[61,62]$.

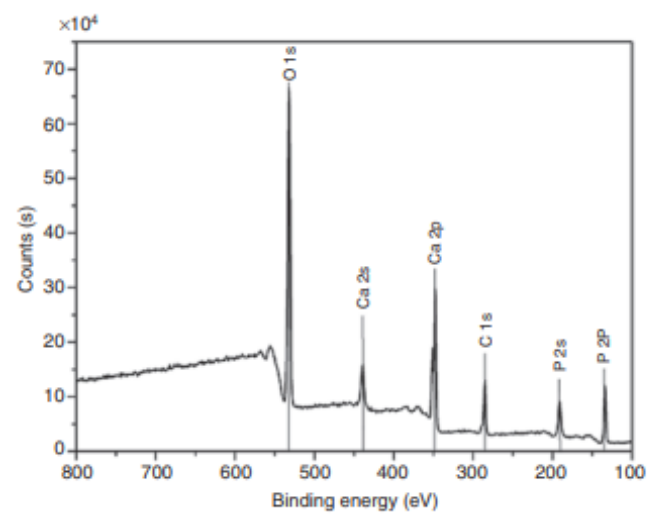

Figure 5: XPS spectra of pure HAp [59]

XPS spectra of pure HAp is presented in Figure 5. The peaks appearing at $134 \mathrm{eV}$ is attributed to $\mathrm{P} 2 \mathrm{p}$ spectra of HAp and those at 532 and $347 \mathrm{eV}$ correspond to $\mathrm{O} 1 \mathrm{~s}$ and $\mathrm{Ca} 2 \mathrm{p}$ respectively. From these values, $\mathrm{Ca} / \mathrm{P}$ (standard value: 1.67 ) ratio in the materials is calculated. These spectra can be resolved into further peaks (under high resolution) with corresponding binding energy values (not shown here). Different functional groups of $\mathrm{HAp}$ i.e. $\mathrm{OH}^{-}, \mathrm{PO}_{4}{ }^{3-}, \mathrm{CO}_{3}{ }^{2-}$ can also be assigned from these values [59].

\section{Morphological characterization}

Surface morphology of HAp derived from biogenic sources (sea squids) and that of synthetic HAp are depicted in Figure 6. The discrete, elongated and somehow spherical particles of HAp can be observed but their agglomeration can hardly be depicted from Figure 6a. On the other hand, porous structure of HAp can be predicted which is essential to provide a favorable environment for cell growth in biomedical applications. Similarly, the synthetic HAp (Figure 6b) also shows discrete HAp particles alongwith slightly agglomerated morphology. From these observations, it is concluded that morphology of bio-derived HAp is suitable for the cell-materials interaction in biomaterials than chemically synthesized HAp $[50,59,63]$. However, it is reported that higher porosity can be obtained mostly from wet chemical methods where as higher crystallinity can be obtained from biogenic sources [27].
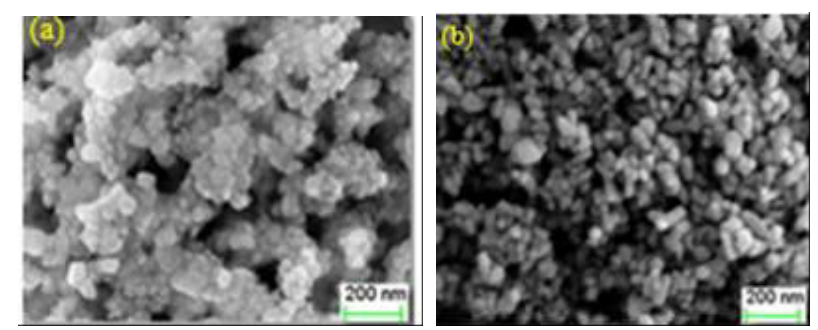

Figure 6: SEM micrographs (a) Squid pen derived HAp and (b) Synthetic HAp [50]

The mechanical property of HAp becomes its wide application in biomaterials, regenerated hard tissues, and in medicine $[15,64,65]$. The mechanical properties of the HAp and $\mathrm{OH}$ carbonated HAp single crystal are different than that of dense HAp ceramic air. It is reported that the bending strength of single-crystal HAp and $\mathrm{OH}$ carbonated HAp is 2.5 times higher than that of dense HAp ceramic air [66]. The mechanical properties of HAp are improved by the preparation of composites (for example; HApchitosan composite, $\mathrm{HAp}$ nano-rods, $\mathrm{HAp}-\mathrm{Al}_{2} \mathrm{O}_{3}$ composites, etc.) $[3,14,17,67]$. The microstructural and mechanical properties of $\mathrm{HAp}-\mathrm{Al}_{2} \mathrm{O}_{3}$ composites were increased when external commercial inert gas (CIG) was applied in increasing increase order [3].

The physicochemical and morphological properties of HAp depend upon its origin and methods of preparation [27]. Natural HAp obtained from animal bones via calcination at $800^{\circ} \mathrm{C}$ possessed high crystallinity whereas synthetic hydroxyapatite 
exhibited low crystallinity, with high porosity and more surface area [27,28,68-70].

\section{Biomedical applications of HAp}

Due to biocompatibility, osteoconductivity, porosity, and similar chemical composition to the natural bones, HAp largely finds biomedical applications especially in dental applications, bone substitution and filling, tissue engineering, drug delivery systems etc. [21,71,72]. Some important biomedical applications of HAp reviewed in this section are illustrated in Scheme 2.

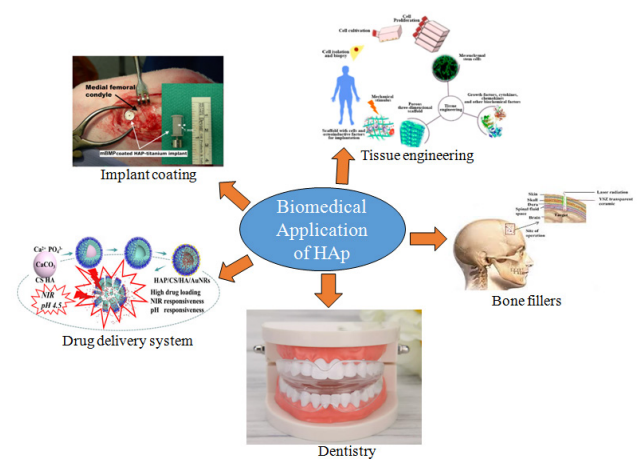

Scheme 2: Illustration of biomedical applications of HAp

Tissue engineering scaffolds and bone fillers

The best therapeutic effect with an artificial bone localization in human body can be attributed only by self-cementing biomaterials. A good scaffold for tissue engineering should be biocompatible, biodegradable, porous and its degradation rate should match the healing rate of new tissue to be used for the construction of new biological tissues [73]. Therefore, HAp can be a promising material for these purposes. Transformation of different morphologies and phases of calcium phosphates into HAp during materials setting further support it in these applications [73]. HAp based biomaterial scaffolds are used in tissue engineering for bio-factors delivery including cells, genes, protein, blood cells, etc [67].

Juhasz et al., incorporated 10 wt.- $\%$ of carbonate substituted nano-HAp particles into poly-2-hydroxy methylmethacrylate/polycaprolactone (PHE-MA/ PCL) hydrogel which exhibited significantly greater cellular activity on human osteoblast than that of pure hydrogel and micro/macro HAp filled hydrogels in terms of bioactivity and exposed surface area [74]. Similarly, Li et al. has reported that nano-size of HAp has more pronounced effect in cell proliferation than its morphology [75].

Similarly, polycaprolactone (PCL)/HAp, polylactide (PLA)/HAp, and poly (propylene fumarate) (PPF/ HAp) scaffold systems are found to enable both in-, vitro and in-vivo tests in bone healing [72]. Liu et al., performed in vitro and in vivo tests of $3 \mathrm{D}$ printed - osteogenic PLA/HAp screw-like scaffolds loaded with mesenchymal stem cells (MSCs) with in the bone tunnel and concluded the promotion of bone growth as well as bone graft [76]. These results open the way for the applications of 3D printed HAp biomaterials in bones and tissue engineering. Ishak and coworkers have reported that $3 \mathrm{D}$ printed $\mathrm{HAp} / \beta$ tri-calcium phosphate (TCP) scaffolds coated with the dipyridamole agents and bone morphogenetic protein-2 (BMP-2), stimulates $\mathrm{A} 2 \mathrm{~A}$ receptors and promotes critical bone defects regeneration [77]. Similarly, nano-HAp/silk fibroin composite scaffolds loaded with bone morphogenetic protein-2 (BMP2) exhibited improved osteogenesis capacity and accelerated early-stage bone formation [14,78-80].

Drug loaded HAp based bioactive nanocomposites are utilized for the treatment of teeth and bone problems and provocative response after surgery or remedial action of diseases [81]. They are particularly utilized for filling voids of bones and drug delivery carriers to keep the burning and infection response in the harmed tissues [82]. HAp metal composites such as HAp/Titanium HAp/Magnesium are commonly used as bone replacement materials than HAp-polymer composites because of the reliable mechanical strength of the metals $[14,71,83]$.

Furthermore, natural bones possess various electric properties i.e piezoelectricity, pyroelectricity, dielectric constant, and ferroelectricity [68]. It is reported that bone derived HAp also exhibits these properties which help to enhance the healing process of large defects in fractured bones [61,62]. Higher dielectric and piezoelectric properties of HAp-metal composites are reported than that of pure HAp $[62,69,70]$. Hence, nano-HAp (derived from bones)/metal (Ti or $\mathrm{Mg}$ ) composites are the promising materials for bone substitution in terms of their electric and mechanical properties.

Nano-HAp with the average particle size in the range of $20 \mathrm{~nm}$ is taken as the best for reconstruction and replacement of bones. Similarly, HAp particles in the range of $40-80 \mathrm{~nm}$ are reported as suitable nanomaterials for these purposes [19].

\section{Drug delivery systems}

HAp can be used as a carrier unit in drug delivery systems for different drugs and proteins. The polarization property of HAp (preferential binding of matrix proteins) as a bio-ceramic is important to form a drug delivery system [84-86]. Many drug delivery systems have been developed using coralline HAp and biodegradable poly(lactic acid) (PLA) [76]. The high stability, adsorption capacity, selectivity, 
degradation resistance, and biocompatibility of HAp make it applicable as an adsorbent and purifying agent for the separation of proteins, nucleic acid, and antibodies $[87,88]$. The rough surface of HAp due to the presence of $\mathrm{Ca}$ and $\mathrm{P}$ constituents facilitates protein binding [89].

Though all of the obligations of biomedical processes are not fulfilled by HAp, it can be applied in different modified forms such as HAp reinforced polymer nanocomposites, HAp integrated ceramics, HAp based hydrogels, and bio-nano-materials, etc. for various applications of drug delivery systems, therapeutics, and cancer treatment $[57,89]$.

\section{Dentistry}

Nano-HAp has bioactive properties and capability of inducing the mineralization process due to which it has been widely used as oral care ingredients. It is incorporated into several products prepared for enamel remineralization and counteract dental hypersensitivity [90]. Nano-HAp is used in various dental domains such as implantology, surgery, direct pulp capping, pulpotomy, dental tissue regeneration, dental drug delivery, periodontology, esthetics, prevention etc. [46,91]. It has a great ability to inhibit both gram-positive and gram-negative bacteria due to which it is used as a coating material for dental implants [91]. HAp-based composite microspheres amoxicillin and erythromycin are released for the treatment of periodontitis [46].

\section{Implants coatings}

Osteogenic property of HAp is the reason for its wide use in implants coating. Metal implants coated with HAp have the ability to form bonds with the host bone tissues [92]. Crystalline nano-HAp shows better biocompatibility, bioactivity, and mechanical performance rather than microcrystalline or bulk HAp, thus, it can be used in designing superior biocompatible implants coating [29]. Many researchers have introduced surface modification strategy using HAp nanoparticles as a bioactive coating on the metallic implants for enhancing bone-bonding ability [93]. HAp is used in the coating of hip, knee, ankle, hand, and spine implants [94]. It is reported that survival rates of HAp-coated implants remain unaffected by the coating along with biological advantages which activate researchers for further investigation of HAp applications in such implants $[94,95]$.

\section{Conclusion}

Based on the above review and summary, it is concluded that HAp, a major component of animal bones and teeth can be synthesized via, various facile and cost effective methods. Wet chemical (precipitation and sol-gel) methods to prepare synthetic HAp and the mechanochemical methods to derive HAp from biogenic sources are recommended in this connection. However, HAp derived from biogenic sources under optimized conditions can have better crystallinity, mechanical, and electric properties as well as better applicable for biomedical applications because of their extra bioactivity, antibacterial activity, presence of essential minerals, and suitable $\mathrm{Ca} / \mathrm{P}$ ratio. Therefore, biogenic sources can be sustainable nano-HAp sources for biomedical applications deserving ecological and environmental significance. Investment of mechanical and thermal energy will be sufficient for the preparation of these high value materials reducing the use of chemical reagents and solvents.

\section{References}

1. L. I. Karbivska, Smolyak, S, S., Karbivskyy, Savchenko, D, A., Romansky, A, O., Pashchenko, E, A., and Teselko P, O., Nanocomposite based on calcium hydroxyapatite and ultrafine graphite, Nanosistemi, Nanomateriali, Nanotechnolgii, 2019,17, 453-464.

2. R. Khairnar, S. Anjum, and M. Mahabole, Development of CNT doped nano-HAp thick film gas sensor, Development, 2014, 3, 253-261.

3. B. Bulut, N. Demirkolol, Z. E. Erkmen, and E. S. Kayalia, Comparision of microstructural and mechanical properties of hydroxyapatite- $\mathrm{Al}_{2} \mathrm{O}_{3}$ composites with commercial inert glass (CIG) addition, Acta Physica Polonica A, 2014.

4. J. Venkatesan \& S-K. Kim, Chitosan composites for bone tissue engineering-an overview, Marine Drugs, 2010, 608-737. DOI: 10.3390/md8082252.

5. F. Chen, Z-C. Wang, and C-J. Lin, Preparation and characterization of nano-sized hydroxyapatite particles and hydroxyapatite/chitosan nanocomposites for use in biomedical materials, Materials Letters, 2002, 57, 858-861.

6. S. Rujitanapanich, P. Kumpapan, and P. Wanjanoi, Synthesis of hydroxyapatite from the oyster shell via precipitation, Energy Procedia, 2014, 56, 112-117. DOI: 10.1016/j.egypro.2014,07,138.

7. N. K. Nga, L. T. Giang, T. Q. Huy, P. H. Viet, and C. Migliaresi, Surfactant-assisted size control of hydroxyapatite nanorods for bone tissue engineering, Colloids and Surfaces B: Biointerfaces, 2013, B116, 666-673. DOI: http://dx.doi.org/10.1016/j. colsurfb.2013.11.001.

8. K. Lin, and J. Chang, Structure and properties of hydroxyapatite for biomedical application, Shanghai Institute of Ceramics, Chinese Academy of Science, 2015, 3-19. http://dx.doi.org/10.1016/B978-178242-033-0.00001-8.

9. A. Haider, S. Haider, S. S. Han, and I-K. Kang, Recent advances in the synthesis, functionalization and biomedical applications of hydroxyapatite: a 
review, Royal Society of Chemistry Advances, 2017 , 7, 7442. DOI: 10.1039/c6ra26124h.

10. A. Pal, S. Paul, A. R. Choudhury, V. K. Balla, M. Das, and A. Sinha, Synthesis of hydroxyapatite from Lates calcarifer fishbone for biomedical applications, Materials Letters, 2017, 203, 89-92. DOI: http:// dx.doi.org/10.1016/j.matlet.2017.05.103.

11. C. Li, A-K. Born, T. Schweizer, M. ZenobiWong, M. Cerruti, and R. Mezzenga, Amyloidhydroxyapatite bone biomimetic composites, Advanced Materials, 2014, 26, 3207-3212. DOI: 10.1002/adma.201306198.

12. G-J. Ding, Y-J. Zhu, C. Qi, B-Q. Lu, F. Chen, and J. Wu, Porous hollow microspheres of amorphous calcium phosphate: soybean lecithin templated microwave-assisted hydrothermal synthesis and application in drug delivery, Journal of Materials Chemistry B, 2015, 3, 1823-1830. DOI: 10.1039/ c4tb01862a.

13.P. Choudhuri, and D. C. Agrawal, Hydroxyapatite coatings for biomaterials, WoodheadPublishing Limited, 2012,84-127.DOI:10.13140/2.1.1858.8809.

14. S. Anil, E. P. Chalisserry, S. Y. Nam, and J. Venkatesan, Biomaterial for craniofacial tissue engineering and regenerative tissue, Advanced Dental Biomaterials, 2019.

15. A. Zamiri, and S. De, Mechanical property of hydroxyapatite single crystals from nanoindentation data, National of Health Institute, 2011, 4(2), 146152. DOI:10.1016/j.jmbbm.2010.11.001.

16. T. M. Mututuvari, A. L. Harkins, and C. D., Tran, Facile synthesis, characterization and antimicrobial activity of cellulose-chitosan-hydroxyapatite composite materials: A potential material for bone tissue engineering, Society for Biomaterials, 2013, 3266-3277. DOI: 10.1002/jbm.a.34636.

17. L. Song, L. Sun, N. Jiang, and Z. Gan, Structural control and hemostatic properties of porous microspheres fabricated by hydroxyapatite-graftpoly(D,L-Lactide) nanocomposites, Composites Science and Technology, 2016, 134, 234-241. DOI: https://doi.org/10.1016/j.compscitech.2016.09.001

18. J. S. Earl, D. J. Wood, and S. J. Milne, Hydrothermal synthesis of hydroxyapatite, Journal Physics: Conference Series, 2006, 26, 268-271. DOI:10.1088/1742-6596/26/1/064.

19. Y. Cai, Y. Liu, W. Yan, Q. Hu, J. Tao, M. Zhang, Z. Shic, and R. Tang, Role of hydroxyapatite nanoparticle size in bone cell proliferation, Journal of Material Chemistry, 2007, 17, 3780-3787.

20. L. Sundarabharathi, H. Parangusan, D. Ponnamma, M. A. A. Al-Maadeed, and M. Chinnaswamy, In-vitro biocompatibility, bioactivity and photoluminescence properties of Eu31/Sr21 dual-doped nanohydroxyapatite for biomedical applications, Journal of Biomedical Materials Research B: Applied Biomaterials, 2018, 1068(6), 2191-2201.

21. C. M. Simonescu, A. Melinescu, M. Ciuca, B. Zarnescu, Removal of copper (II) ions from aqueous solutions by hydroxyapatite-based materials prepared from eggshells, Revista de Chimie, 2019, 70(6), 1897-1902.

22. N. K. Nga, N. T. T. Chau, and P. H. Viet, Facile synthesis of hydroxyapatite nanoparticles mimicking biological apatite from eggshells for bone-tissue engineering, Colloids and Surfaces B: Biointerfaces, 2018, 172, 769-778. DOI: https://doi.org/10.1016/j. colsurfb.2018.09.039.

23. Q. Hu, Z. Tan, Y.Liu, J. Tao, Y. Cai, M. Zhang, H. Pan, X. Xua, and R. Tang, Effect of crystallinity of calcium phosphate nanoparticles on adhesion, proliferation, and differentiation of bone marrow mesenchymal stem cells, Journal of Materials Chemistry, 2007, 17, 4690-4698.

24. M. Zandi, H. Mirzadeh, C. Mayer, H. Urch, M. B. Eslaminejad, F. Bagheri, and H. Mivehchi, Biocompatibility evaluation of nano-rod hydroxyapatite/gelatin-coated with nano-HAp as a novel scaffold using mesenchymal stem cells, Journal of Biomedical Materials Research Part A, 2009, 1244-1255.

25. N. S. Al-Qasas, and S. Rohani, Synthesis of pure hydroxyapatite and the effect of synthesis conditions on its yield, crystallinity, morphology and mean particle size, Separation Science and Technology, 2005, 40(15) 3187-3224, DOI: 10.1080/01496390500385400.

26. N. Y. Mostafa, Characterization, thermal stability and sintering of hydroxyapatite powders prepared by different routes, Materials Chemistry and Physics, 2005, 94, 333-341.

27. E. Barbero, J. Fernandez-Saez, and C. Navarro, Statistical analysis of the mechanical properties of composite materials, Composites, 2000, 31(5), 375-381. DOI: https://doi.org/10.1016/S13598368(00)00027-5.

28. A. Sobczak-Kupiec, D. Malina, R. Kijkowska, and Z. Wzorek, Comparative study of hydroxyapatite prepared by the authors with selected commercially available ceramics, Digest Journal of Nanomaterials and Biostructures, 2012, 7, 385-391.

29. G. Pandey, K. Dhakal, A. Singh, S. Dhungel, and R. Adhikari, Facile methods of preparing pure hydroxyapatite nanoparticles in ordinary laboratories, BIBECHANA, 2021, 18(1), 83-90. DOI: https://doi.org/10.3126/bibechana.v18i1.29600.

30. S. Mondal, G. Hoanga, P. Manivasagana, M. S. Moorthya, H. H. Kima, T. T. V. Phana, and J. Oh, Comparative characterization of biogenic and chemical synthesized hydroxyapatite biomaterials for potential biomedical application, Material Chemistry and Physics, 2019, 228, 244-356. DOI: https://doi. org/10.1016/j.matchemphys.2019.02.021.

31. D. O. Obada, E. T. Dauda, J. K. Abifarin, D. Dodoo-Arhin, and N. D. Bansod, Mechanical properties of the natural hydroxyapatite using low cold compaction pressure: effect of sintering temperature, Materials Chemistry and Physics, 
2020, 239, 122099. DOI: https://doi.org/10.1016/j. matchemphys.2019.122099.

32. S. Mondal, S. V. Dorozhkin and U. Pal, Recent progress on fabrication and drug delivery applications of nanostructured hydroxyapatite, WIREs Nanomedcine and Nanobiotechnology, 2018, 10, 1-32. DOI: 10.1002/wnan.1504.

33. F. A. C. Andrade, L C. O. Vercik, F. J. Monteiro, and E. C. S. Rigo, Preparation, characterization and antibacterial properties of silver nanoparticleshydroxyapatite composites by a simple and ecofriendly method, Ceramics International, 2016, 42(2), 2271-2280.

34. I-S. Kim, and P. N. Kumta, Sol-gel synthesis and characterization of nanostructured hydroxyapatite powder, Material Science and Engineering: B, 2004, 111, 232-236. DOI:10.1016/j.mseb.2004.04.011.

35. H. Zhou, M. Yang, S. Hou, and L. Deng, Mesoporous hydroxyapatite nanoparticles hydrothermally synthesized in aqueous solution with hexametaphosphate and tea polyphenols, Material Science and Engineering: $C, 2017,71,439-445$. DOI: http://dx.doi.org/10.1016/j.msec.2016.10.040.

36. D. Milovac, G. G. Ferrer, M. Ivankovic, and H. Ivankovic, PCL-coated hydroxyapatite scaffold derived from cuttlefish bone: morphology, mechanical properties and bio-activity, Material Science and Engineering: $C, 2014,34,437-445$. DOI: http://dx.doi.org/10.1016/j.msec.2013.09.036.

37. S. Utara, and J. Klinkaewnarong, Sonochemical synthesis of nano-hydroxyapatite using natural rubber latex as a templating agent, Ceramics International, 2015, 41(10), 14860- 14867. DOI: 10.1016/J.CERAMINT.2015.08.018.

38. S. Amin, T. Siddique, M. Mujahid, and S. Shah, Synthesis and characterization of nanohydroxyapatite using reverse microemulsions as nanoreactors, Journal of Chemical Society Pakistan, 2015, 37(1), 79-85.

39. M. B. Koirala, T. D. T. Nguyen, A. Pitchaimani, S-O. Choi, and S. Aryal, Synthesis and characterization of biomimetic hydroxyapatite nanostructure using chemical gradient across the lipid bilayer. $A C S$ Applied Material and Interfaces, 2015, 7(49), 27382-27390. DOI:10.1021/acsami.5b09042.

40. M. Rajkumar, N. M. Sundaram, V. Rajendran, Preparation of size-controlled, stoichiometric and bioresorbable hydroxyapatite nanorod by varying initial $\mathrm{pH}, \mathrm{Ca} / \mathrm{P}$ ratio and sintering temperature, Digest Journal of Nanomaterials and Biostructures, 2011, 6(1), 169-179.

41. G. J. E. Poinern, R. Brundavanam, X. T. Le, S. Djordjevic, M. Prokic, and D. Fawcett, Thermal and ultrasonic influence in the formation of nanometerscale hydroxyapatite bio-ceramic, International Journal of Nanomedicine, 2011, 6, 2083-2095. DOI: http://dx.doi.org/10.2147/IJN.S24790.

42. M. H. Santos, M. D. Oliveira, L. P. D. F. Souza, H. S. Mansur, and W. L. Vasconcelos, Synthesis control and characterization of hydroxyapatite prepared by a wet precipitation process, Materials Research, 2004, 7, 625-630. DOI: https://doi.org/10.1590/S151614392004000400017.

43. K. Dhanaraj, and G. Suresh, Conversion of waste sea shell (Anadara granosa) into valuable nanohydroxyapatite (nHAp) for biomedical applications, Vacuum, 2018. DOI: 10.1016/j. vacuum.2018.03.021 (Accepted Manuscript).

44. J. Zhang, M. Iwasa and D. Jiang, Size-controlled hydroxyapatite nanoparticles as self-organized organic-inorganic composite materials, Advances in Science and Technology, 2006, 53, 32-37. https:// doi.org/10.4028/www.scientific.net/AST.53.32.

45. M. Sadat-Shojai, M-T. Khorasani, E. DinpanahKhoshdargi, and A. Jamshidi, Synthesis method for nanosized hydroxyapatite with diverse structures, Acta Biomaterilia, 2013, 9, 7591-7621. DOI: http:// dx.doi.org/10.1016/j.actbio.2013.04.012.

46. S. Mazumder, A. K. Nayak, T. J. Ara, and M. S. Hasnain, Hydroxyapatite composites for dentistry, Application of Nanocomposite Materials in Dentistry, 2019, 123-143. DOI: https://doi. org/10.1016/B978-0-12-813742-0.00007-9.

47. M. H. Fathi, and A. Hanifi, Evaluation and characterization of nanostructure hydroxyapatite powder prepared by simple sol-gel method, Materials Letters, 2007, 61, 3978-3983. DOI:10.1016/j. matlet.2007.01.028.

48. U. Vijayalakshmi, and S. Rajeswari, Preparation and characterization of microcrystalline hydroxyapatite using sol-gel method, Trends Biomaterial Artificial Organs, 2006, 19, 57-62.

49. S. Sasikumar and R. Vijayaraghavan, Lowtemperature synthesis of nanocrystalline hydroxyapatite from eggshells by combustion method, Trends in Biomaterials \& Artificial Organs, 2006, 19(2), 70-73.

50. M. Mathina, E. Shinyjoy, L. Kavitha, P. Manoravi and D. Gopi, A comparative study of naturally and synthetically derived bioceramics for biomedical applications, Materials Today Proceeding, 2020, 26, 3600-3603. DOI: https://doi.org/10.1016/j. matpr.2019.08.222.

51. M. Ozawa, and S. Suzuki, Microstructural development of natural hydroxyapatite originated from fish-bone waste through heat treatment, Journal of the American Ceramic Society, 2002, 85, 1315-1317. DOI: https://doi. org/10.1111/j.1151-2916.2002.tb00268.x.

52. L. Xiaoying, F. Yongbin, G. Dachun, and C. Wei, Preparation and characterization of natural hydroxyapatite from animal hard tissues, Key Engineering Materials, 2007, 342-343, 213-216.

53. J. K. Odusote, Y. Danyuo, A. D. Baruwa, and A. A. Azeez, Synthesis and characterization of hydroxyapatite from bovine bone for production of dental implants, Journal of Applied Biomaterials \& Functional Materials, 2019, 1-7. DOI: 
$10.1177 / 2280800019836829$.

54. N. L. Bhandari, G. Bhandari, S. Bista, B. Pokhrel, K. Bist, and K. Dhakal, Degradation of fundamental polymers/plastics used in daily life: a review, BIBECHANA, 2021, 18(1), 240-253. DOI: https:// doi.org/10.3126/bibechana.v18i1.29619.

55. H. L. Jaber, A. S. Hammood, and N. Parvin, Synthesis and characterization of hydroxyapatite powder from natural camelus bone, Journal of the Australian Ceramic Society, 2018, 54(1), 1-10. DOI: 10.1007/ s41779-017-0120-0.

56. F. Sharifianjazi , A. Esmaeilkhanian, M. Moradi, A. Pakseresht, M. Shahedi Asl, H. Karimi-Maleh, H. Won Jang, M. Shokouhimehr and R. S. Varma, Biocompatibility and mechanical properties of pigeon bone waste extracted natural nanohydroxyapatite for bone tissue engineering, Materials Science \& Engineering B, 2021, 264, 114950. https://doi. org/10.1016/j.mseb.2020.114950.

57. X. Guo, L. Yu, L. Chen, H. Zhang, L. Peng, X. Guo, and W. Ding, Organoamine-assisted biomimetic synthesis of faceted hexagonal hydroxyapatite proliferation, Material Chemistry, 2014, B2, 17601763.

58. P. A. F. Sossa, B. S. Giraldo, B. C. G. Garcia, E. R. Parra, and P. J. A. Arango, Comparative study between natural and synthetic Hydroxyapatite: structural, morphological and bioactivity properties, Matéria (Rio Rio de Janeiro), 2018, 23(4), 1517-7076. DOI: https://doi.org/10.1590/s1517707620180004.0551.

59. A. Anwar, Q. Kanwal, S. Akbar, A. Munawar, A. Durrani, and M. H. Farooq, Synthesis and characterization of pure and nanosized hydroxyapatite bioceramics, Nanotechnology Reviews, 2017, 6(2), 149-157.

60. S. Ramesh, Z. Z. Looa, C. Y. Tana, W. J. Kelvin Chew, Y. C. Ching, F. Tarlochan, H. Chandran, S. Krishnasamy, L. T. Bang and A. A. D. Sarhan, Characterization of biogenic hydroxyapatite derived from animal bones for biomedical applications, Ceramics International, 2018, 44, 10525-10530. https://doi.org/10.1016/j.ceramint.2018.03.072.

61. A. Das, and D. Pamu, A comprehensive review on electrical properties of hydroxyapatite based ceramic composites, Material Science and Engineering C, 2019, 101, 539-563. DOI: https://doi.org/10.1016/j. msec.2019.03.077.

62. A. E. Hannora, and M. M. Mostafa, Structure and electrical properties of hydroxyapatite/ titania nanocomposites by high energy vibratory ball milling, mining, Petroleum and Metallurgical Engineering (MPMM12), 2014.

63. P. Terzioğlu, H. Öğüt and A. Kalemtaş, Natural calcium phosphates from fish bones and their potential biomedical applications, Materials Science \& Engineering C, 2018, 91, 899-911. https://doi.org/10.1016/j.msec.2018.06.010.

64. W. Pyda, A. Sl' Osarczyk, Z. Paszkiewicz, A. Rapacz-
Kmita, M. Haberko, and A. Pyda, Polycrystalline hydroxyapatite material reinforced with zirconia inclusions, Composites, 2001, 1-2, 133-136.

65. C. Piconi, and G. Maccauro, Review: zirconia as a ceramic biomaterial, Biomaterials, 1999, 20, 1-25.

66. K. Teraoka, A. Ito, K. Maekawa, K. Onuma, T. Tateishi, and S. Tsutsumi, Mechanical properties of hydroxyapatite and $\mathrm{OH}$-carbonated hydroxyapatite single crystals, Journal of Dental Research, 1998, 77,1560 .

67. H. Zhang, and B. W. Darvell, Morphology and structural characteristics of hydroxyapatite whiskers: effect of the initial $\mathrm{Ca}$ concentration, $\mathrm{Ca} / \mathrm{P}$ ratio and pH, Acta Biomaterilia, 2011, 7, 2960-2968 DOI: https://doi.org/10.1016/j.actbio.2011.03.020.

68. A. K. Dubey, and K. Balani, Electrically active biocomposites as smart scaffolds for bone tissue engineering, Woodhead Publishing Limited, 2012, 537-570.

69. C. R. Bowen, J. I. Gittings, I. G. Turners, F. Baxter, and J. B. Chaudhuri, Dielectric and piezoelectric properties of the hydroxyapatite- $\mathrm{BaTiO}_{3}$ composites, Applied Physics Letters, 2006, 89, 132906-1-3. DOI: 10.1063/1.2355458.

70. M. Tavangar, F. Heidari, R. Hayati, F. Tabatabaei, D. Vashaee, and L. Tayebi. Manufacturing and characterization of mechanical, biological and dielectric properties of hydroxyapatite-barium titanate nanocomposite scaffolds, Ceramics International, 2020, 46(7), 9086-9095.

71. K. Lin, and J. Chang, Structure and properties of hydroxyapatite for biomedical application, Shanghai Institute of Ceramics, Chinese Academy of Science, 2015. DOI: http://dx.doi.org/10.1016/B978-178242-033-0.00001-8.

72. A. Szczes, L. Holysz, and E. Chibowski, A comparative study of naturally and synthetically derived bioceramics for biomedical applications, Advances in Colloid and Interface Science, 2017, 249, 321-330. DOI: http://dx.doi.org/10.1016/j. cis.2017.04.007.

73. M. Otsuka, Y. Matsuda, Y. Suwa, J. L. Fox, and W. I. Higuchi, Effect of particle size of metastable calcium phosphates on the mechanical strength of a novel self-setting bioactive calcium phosphate cement, Journal of Biomedical Materials Research, 1995, 29, 25-32. DOI: CCC 0021-9304/95/01002508.

74. J. A. Juhasz, S. M. Best, and W. Bonfield, Preparation of novel bioactive nano-calcium phosphate-hydrogel composites, Science and Technology of Advanced Material, 2010, 11(1), 1-7. DOI: 10.1088/14686996/11/1/014103.

75. B. Li, B. Guo, H. Fan, and X. Zhang, Preparation of nano-hydroxyapatite particles with different morphology and their response to highly malignant melanoma cells in vitro, Applied Surface Science, 2008, 255, 357-360. http://dx.doi.org/10.1016/j. apsusc.2008.06.114. 
76. A. Liu, G. H. Xue, M. Sun, H-F. Sha, C-Y. Ma, Q. Gao, Z. Gou, S. Yan, Y. Liu, and Y. He, 3D printing surgical implants at the clinic: an experimental study on anterior cruciate reconstruction, National Library of Medicine, 2016, 6, 1-13. DOI: 10.1038/ srep21704.

77. S. Ishack, A. Mediero, T. Wilder, J. L. Ricci, and B. N. Cronstein, Bone regeneration in critical bone defects using three-dimensionally printed $\beta$-tricalcium phosphate/hydroxyapatite scaffolds is enhanced by coating scaffolds with either dipyridamole or BMP2, Journal of Biomedical Material Resources, Part B, Applied Biomaterials, 2017, 105(2), 366-375. DOI: 10.1002/jbm.b.33561.

78. Z. Ding, Z. Fan, X. Huang, Q. Lu, W. Xu, and D. L. Kaplan, Silk-hydroxyapatite nanoscale scaffolds with programmable growth factor delivery for bone repair, ACS Applied Material and Interface, 2016, 8(37), 24463-24470. DOI: 10.1021/acsami.6b08180.

79. S. K. Nandi, B. Kundu, J. Mukhurjee, A. Mahato S. Datta, and V. K. Balla, Converted marine coral hydroxyapatite implants with growth factors: in vivo bone regeneration, Materials Science and Engineering, $C$, Materials for biological Application, 2015, 49, 816-823. DOI: 10.1016/j. msec.2015.01.078.

80. Q. Chen, C. Zhu, and G. A. Thouas, Progress and challenges in biomaterials used for bone tissue engineering: bioactive glasses and elastomeric composites, Progress in Biomaterials, 2012, 1, 2. DOI: 10.1186/2194-0517-1-2.

81. A. S. Budiatin, M. Zainuddin, and J. Khotib, Biocompatible composite as gentamicin delivery system for osteomyelitis and bone regeneration, International Journal PharmacyandPharmaceutical Sciences, 2014, 6(3), 223-226.

82. I. J. Macha, B. Ben-Nissan, J. Santos, S. Cazalbou, and B. Milthorpe, Hydroxyapatite/PLA biocomposites thin films for slow drug delivery of antibiotics for the treatment of bone and implantrelated infections, Key Engineering Materials, 2016, 696, 271-276 DOI: https:/www.researchgate.net/ publication/301197687.

83. M. Prakasam, J. Locs, K. N. Ancane, D. Loca, A. Largeteau, and L. B. Cimdina, Fabrication properties and applications of dense hydroxyapatite: a review, Journal of Functional Biomaterials, 2015, 6, 10991140. DOI: $10.3390 / \mathrm{jfb6041099.}$

84. J. Kirkham, S. J. Brookes, R. C. Shore, S. R. Wood, D. A. Smith, J. Zhang, Chen, and C. Robinson, Physicochemical properties of crystal surfaces in matrix-mineral interactions during mammalian biomineralization C, Curr Opin Colloid Interface Science, 2002, 7, 124-132.
85. J. Kolmasn, S. Krukowski, A. Laskus, and M. Jurkitewicz, Synthetic hydroxyapatite in pharmaceutical applications, Ceramics International, 2016, 42, 2472-2487. DOI: http:// dx.doi.org/10.1016/j.ceramint.2015.10.048.

86. M. S. Alhammad, Nanostructure hydroxyapatite based ceramics by sol-gel method, Journal of Alloy and Compound, 2016, 661, 251-256. DOI: http:// dx.doi.org/10.1016/j.jallcom.2015.11.045.

87. C. J. Morrison, P. Gagnon, and S. M. Cramer, Purification of monomeric $\mathrm{mAb}$ from associated aggregates using selective desorption chromatography in hydroxyapatite systems, Biotechnology and Bioengineering, 2011, 108, 813821. DOI: https://doi.org/10.1002/bit.22971.

88. S. Kano, A. Yamazaki, R. Otsuka, M. Ohgaki, M. Akao, and H. Aoki, Application of hydroxyapatitesol as a drug carrier, Bio-Medical Materials and Engineering, 1994, 4, 283-290. DOI: 10.3233/ BME-1994-4404.

89. W. Gu, C. Wu, J. Chen, and Y. Xiao, Nanotechnology in the targeted drug delivery for bone diseases and bone regeneration, International Journal of Nanomedicine, 2013, 8, 2305-2317. DOI: 10.2147/ IJN.S44393. Epub 2013 Jun 25.

90. C. C. Coelho, L. Grenho. P. S. Gomes, P. A. Quadros, and M. H. Fernandes, Nano-hydroxyapatite in oral care cosmetics: characterization and cytotoxicity assessment, Scientific Reports, 2019, 9(1) 1-10. DOI: https://doi.org/10.1038/s41598-019-47491-z.

91. I. R. Bordea, S. Candrea, G. T. Alexescu, S. Bran, M. Baciut, G. Baciut, O. Lucaciu, C. M. Dinu, and D. A. Todea, Nano-hydroxyapatite use in dentistry: a Systematic review, Drug Metabolism Reviews, 2020, 52(2), 319-332. DOI: https://doi.org/10.1080 /03602532.2020.1758713.

92. S. Bose, S. Tarafder, and A. Bandyaopadhyay, Hydroxyapatite coatings for metallic implants, Woodhead Publishing, 2015, 143-157. DOI: 10.1016/ B978178242033000007-9.

93. W. S. W. Harun, R. I. M. Asri, A. B. Sulong, S. A. C. Ghani, and Z. Ghazalli, Hydroxyapatite-based coating on the biomedical implant, Intech Open Science Open Mind, 2018. DOI: http://dx.doi. org/10.5772/intechopen.71063.

94. I. R. Gibson, Synthetic hydroxyapatite for bonehealing applications, Hydroxyapatite (HAp) for Biomedical Application, 2015, 269-287. DOI: 10.1016/B978178242033000012-2.

95. J. J. Lee, L. Rouhfar, and O. R. Beirne, Survival of hydroxyapatite-coated implants: a meta-analytic review, Journal of Oral and Maxillofacial Surgery, 2000, 58, 1372-1379. DOI: https://doi.org/10.1053/ joms.2000.18269. 